\title{
Concurrent musculoskeletal and soft tissue pain in the upper extremity can affect the treatment and prognosis of carpal tunnel syndrome: redefining a common condition
}

This article was published in the following Dove Press journal:

Journal of Pain Research

24 October 2017

Number of times this article has been viewed

\section{Reynaldo P Lazaro'}

Thomas S Eagan ${ }^{2}$

'Electroneuromyography Clinic, Oneonta, NY, USA; ${ }^{2}$ Department of Orthopedic Surgery, Orthopedic and Hand Surgery and Wellness Center, Nathan Littauer Hospital, Gloversville, NY, USA
Correspondence: Reynaldo P Lazaro Neurology and Electroneuromyography Clinic, 4I-45 Dietz Street, Oneonta, NY 13820, USA

Tel +l 6074328272

Fax + I $60744 \mid 505$ |

Email aacmbbilling@gmail.com
Objective: To demonstrate the importance of recognizing and separating nonmedian nerverelated symptoms from those related to median nerve compression at the carpal tunnel.

Methods: The records of 80 patients, aged 31-82 years (39 males and 41 females), who had undergone median nerve decompression using open and endoscopic release surgery, were reviewed. Peripheral electrodiagnostic studies were performed in all patients prior to surgery. Those whose nonmedian nerve-related symptoms, also known as musculoskeletal and soft tissue pain and tenderness, persisted postoperatively, were referred to another electrodiagnostic study to reassess the median nerve function at the carpal tunnel. Peripheral electrodiagnostic studies were deemed unnecessary for patients with exclusively median nerve-related symptoms who improved dramatically following surgery. Included from the study were cases whose presenting symptoms were primarily referrable to median nerve dysfunction with or without associated musculoskeletal pain. Cases that were excluded were those whose symptoms were related to various primary conditions. Outcome of surgery was reviewed and correlated with symptoms related to median nerve compression and musculoskeletal irritation, and with electrodiagnostic abnormalities.

Results: Complete resolution of symptoms, following surgery, occurred in patients with clinical and electrophysiologic signs of median nerve compression but without significant symptoms of musculoskeletal irritation. Those with concurrent and prominent musculoskeletal and soft tissue pain had variable results, both favorable and unfavorable, including three who developed signs and symptoms of complex regional pain syndrome.

Conclusion: The symptoms related to median nerve compression at the carpal tunnel and the symptoms related to musculoskeletal and soft tissue irritation are two different symptom complexes that have important diagnostic and therapeutic considerations. We would like to propose that "true carpal tunnel syndrome" symptoms, those that are exclusively median nerve related, should be considered a distinct entity. When musculoskeletal and soft tissue pain is more prominent and dominates the overall clinical presentation, the term "mechanical stress syndrome" is more appropriate.

Keywords: median nerve, carpal tunnel syndrome, musculoskeletal pain, soft tissue pain, complex regional pain, mechanical stress syndrome, repetitive hand motion

\section{Introduction}

Signs and symptoms of carpal tunnel syndrome (CTS) are attributed to compression of the median nerve by the thickened ligaments and tendon sheaths that form the wall 
of the tunnel at the wrist. The sensory symptoms are both negative and positive. The negative sensory symptom consists mainly of loss of sensation (numbness) in the lateral three digits and lateral half of the fourth digit. Positive sensory symptoms are manifested by paresthesias and by nocturnal burning pain in the fingers and wrist. They sometimes extend to the forearm and arm. These symptoms occur pari passu with one another. Characteristically, the cutaneous sensation over the thenar eminence is preserved due to sparing of the palmar cutaneous branch, which does not enter the tunnel, and it travels superficial to the flexor retinaculum of the hand and divides into a lateral and a medial branch. When the motor fibers become affected, as the condition progresses, the thenar muscles become weak and atrophic but the flexion of the interphalangeal joint of the thumb remains normal because of sparing of the flexor pollicis longus muscle, a muscle innervated by the median nerve, via anterior interosseous branch, proximal to the tunnel.

Nonmedian nerve-related symptoms, consisting of pain and local tenderness at the wrist, forearm, arm, and shoulder, are generated from the inflamed tendons and ligaments and strained muscles and joints. Sometimes they accompany or dominate the symptoms generated from the compromised median nerve at the wrist. These symptoms characteristically intensify during physical activity. To some health care providers and laypersons, musculoskeletal pain and tenderness are usually considered part and parcel of the symptom complex of CTS. Although the symptoms of median nerve compression and those of musculoskeletal irritation are the results of mechanical stress, the amalgamation of these symptoms can affect the treatment and prognosis of this condition. It is noteworthy that either one can be more prominent and disabling; hence, there is a need to differentiate these two symptom complexes.

One observational study ${ }^{1}$ had shown that decompressing the median nerve at the tunnel may not necessarily result in resolution of musculoskeletal and soft tissue pain, an indication that these symptoms are clinically distinct from each other. The authors would like to propose that "true CTS" should apply only to those cases in which the median nerve-related symptoms are the main or sole manifestations. However, when musculoskeletal pain and symptoms related to median nerve compression occur together, or the former being more prominent and disabling, the proper term should be mechanical stress syndrome, an inclusive term or situation that requires a different treatment approach and has a different prognosis. We conducted a retrospective study of 80 cases of this common condition that we had evaluated and treated over the past 10 years.

\section{Methods}

One of the authors (RPL), a board-certified neurologist and electroneuromyographer, had received referrals from various surgical specialists for electrodiagnostic study (using Cadwell Sierra 11 Wedge EMG NCV System), including referrals from the co-author (TSE), a board-certified orthopedic and hand surgeon who performed carpal tunnel release surgery on 20 of 80 patients studied, and from other orthopedic and plastic surgeons who performed surgery in the remaining 60 patients. The study period extended from 2007 to 2017.

Various cases of work-related sensory symptoms in the upper extremity, particularly in the wrist, were included in the study: patients were engaged in various occupations that require repetitive hand motion. Some cases included in the study with classic signs of CTS had no clear identifiable risk factors. Patients with diabetes without overt signs of polyneuropathy including those with hypothyroidism, rheumatoid arthritis, and those with previous history of wrist fractures were also included. These conditions were included because the presenting and disabling symptoms were referable to the upper extremities, particularly in the hands. Those with clear signs and symptoms of cervical radiculopathy due to herniated discs and/or significant degenerative changes in the cervical spine, brachial plexopathy, concurrent mononeuropathies, active arthropathies in the elbow and shoulder, fibromyalgia, Lyme disease, malignancy, musculoskeletal pain related to vehicular accidents, peripheral neuromuscular and central nervous system disorders, and thoracic outlet syndrome were excluded from the study. We felt it was necessary to exclude these conditions since the prominent and predominant symptoms in these patients were related to the primary conditions and not to the CTS. Those with persistent signs of median nerve dysfunction following surgery and considered as treatment failure, along with those who developed postoperative infection, were also excluded. A total of 80 cases, 60 unilateral and 20 bilateral, were studied and were followed for 6 months to 2 years, postoperatively.

The clinical diagnosis of CTS was based on classic symptoms, namely nocturnal numbness, paresthesias, and burning pain in the median nerve distribution. These symptoms were reproduced or induced by driving a motor vehicle or when performing repetitive activities. The sensation over the thenar eminence and the strength of the flexor pollicis longus muscle were intact. Tinel and Phalen signs were clearly present in $70 \%$ of patients. 
All patients had electrodiagnostic abnormalities (Table 1) consistent with CTS (distal median nerve motor latency of at least $4.2 \mathrm{~ms}$, normal $[\mathrm{N}]=<4.0 \mathrm{~ms}$; distal antidromic sensory latency of at least $3.6 \mathrm{~ms}, \mathrm{~N}=<3.5 \mathrm{~ms}$, measured at the peak of the response at either second or fourth fingers, $13 \mathrm{~cm}$ from the wrist). None had abnormal proximal velocities or abnormal ulnar or radial nerve conduction results. Monopolar needle electromyography was performed if there was a question of cervical radiculopathy or brachial plexopathy. All patients underwent clinical peripheral neuromuscular examination performed by RPL prior to electrodiagnostic study. Nerve conduction studies were performed using standard techniques for transcutaneous stimulation and recording with surface electrodes, as previously described. ${ }^{2,3}$ Limb temperature was routinely maintained at $36^{\circ} \mathrm{C}$ using a heat lamp and monitored with a cutaneous thermocouple. Radiological imaging was performed using magnetic resonance imaging (MRI) in some patients when necessary.

Median nerve decompression was performed either by open or endoscopic release surgery after failure of 4-6 weeks of conservative therapy including physical therapy, analgesics, and workplace ergonomics. Surgery was performed, without conservative therapy, in some patients when the clinical and electrodiagnostic abnormalities were quite severe. These patients were treated nonsurgically in previous years before surgery was performed. Trigger fingers and De Quervain tenosynovitis encountered in five and four patients, respectively, were treated separately.

Those symptoms that resolved following surgery and those that did not were correlated with the presence or absence of median nerve-related symptoms and musculoskeletal and soft tissue pain, and with the degree or severity of each symptom complex.

The Chesapeake Institutional Review Board (IRB) in Columbia, MD, USA, had determined that the present study does not constitute human subject research and, therefore, does not require IRB oversight and it was deemed unnecessary to obtain written informed consent from patients described in this study.

\section{Results}

The 50 patients ( 20 operated by TSE and 30 by the other surgeons, 38 unilateral and 12 bilateral) whose symptoms were related solely to median nerve compression (numbness, paresthesias, and burning pain) improved dramatically following open or endoscopic release surgery. These patients had median nerve motor and sensory nerve latencies that were considerably more delayed and the sensory responses dispersed and reduced than were those with musculoskeletal and tenderness as the main disabling and prominent symptoms; the latter had either near normal or mildly delayed median nerve latencies.

The 30 patients, 22 unilateral and 8 bilateral, with prominent pain and local tenderness in the upper extremity were referred back to another electrodiagnostic study, 6 months to a year, following surgery: they (including those with bilateral symptoms) had persistent local pain and tenderness in the affected extremity, especially at the wrist and forearm. All these patients except seven showed normalization of electrodiagnostic study and significant resolution of median nerve-related symptoms. The electrodiagnostic study in these seven patients (five unilateral and two bilateral) showed no significant changes in abnormalities but they did report reduction in the frequency of their median nerve-related symptoms which were overshadowed by persistent musculoskeletal pain. Three patients developed cold sensation, intermittent swelling, red discoloration, and burning pain in the affected wrist and fingers, all consistent with complex regional pain syndrome (CRPS). These patients were barely able to complete the second electrodiagnostic study due to pain. Summary of the results is shown in Table 2 .

Table I Median nerve electrodiagnostic study

\begin{tabular}{|c|c|c|}
\hline & $\begin{array}{l}\text { True CTS median nerve-related } \\
\text { symptoms only, } 50 \text { patients }\end{array}$ & $\begin{array}{l}\text { Mechanical stress syndrome median } \\
\text { nerve-related symptoms combined with } \\
\text { musculoskeletal and soft tissue pain, } 30 \\
\text { patients }\end{array}$ \\
\hline Motor latency & Range: $5.2-12.5 \mathrm{~ms}(\mathrm{~N}<4.0)$ & Range: $4.3-5.1 \mathrm{~ms}$ \\
\hline Sensory latency & 4. I-7.0 ms $(\mathrm{N}<3.5)$ & $3.7-4.0 \mathrm{~ms}$ \\
\hline Sensory amplitude & I.5-22.0 $\mu \mathrm{V}(\mathrm{N}>10)$ & $23.0-45.0 \mu \mathrm{V}$ \\
\hline Dispersed sensory responses & Present/absent responses in 15 & Present but mild \\
\hline Monopolar needle EMG & $\begin{array}{l}\text { Not performed because of clear diagnosis and } \\
\text { absence of radicular deficits }\end{array}$ & Performed in 15 with normal findings \\
\hline Ulnar and radial nerve conduction study & Normal & Normal \\
\hline
\end{tabular}

Abbreviation: CTS, carpal tunnel syndrome. EMG, electromyography. 
Table 2 Summary of patient profiles

\begin{tabular}{|c|c|c|}
\hline & $\begin{array}{l}\text { CTS without musculoskeletal pain } \\
\text { (True CTS) }\end{array}$ & $\begin{array}{l}\text { CTS with musculoskeletal pain } \\
\text { (mechanical stress) }\end{array}$ \\
\hline Number of patients & 50 (38 unilateral, 12 bilateral) & 30 (22 unilateral, 8 bilateral) \\
\hline Surgical technique & Open and endoscopic & Open and endoscopic \\
\hline Outcome of surgery & $\begin{array}{l}\text { Complete resolution of median nerve-related } \\
\text { symptoms }\end{array}$ & $\begin{array}{l}\text { Partial to complete resolution of median } \\
\text { nerve-related symptoms with persistence of } \\
\text { musculoskeletal and soft tissue pain }\end{array}$ \\
\hline History of preoperative CRPS & None & None \\
\hline Postoperative CRPS & None & Developed in three patients \\
\hline Coexisting medical disorders & $\begin{array}{l}\text { Diabetes and hypothyroidism in three and } \\
\text { rheumatoid arthritis in two }\end{array}$ & None \\
\hline $\begin{array}{l}\text { Presence of cervical radiculopathy, brachial } \\
\text { plexopathy, and thoracic outlet syndrome }\end{array}$ & None & None \\
\hline $\begin{array}{l}\text { No. of patients with past history of wrist } \\
\text { fracture }\end{array}$ & 6 & None \\
\hline $\begin{array}{l}\text { No. of patients with past history of repetitive } \\
\text { hand motion }\end{array}$ & Job related: I0; not job related: 40 & Job related: I9; not job related: II \\
\hline Postsurgical infection & None & None \\
\hline Abnormalities in wrist MRI & None & None \\
\hline No. of patients with De Quervain tenosynovitis & None & 4 \\
\hline No. of patients with trigger fingers & 2 & 3 \\
\hline $\begin{array}{l}\text { No. of patients who received steroid injection } \\
\text { to the wrist }\end{array}$ & None & $\begin{array}{l}3 \text {, with temporary relief of median nerve-related } \\
\text { symptoms and musculoskeletal pain }\end{array}$ \\
\hline
\end{tabular}

Abbreviations: CRPS, complex regional pain syndrome; CTS, carpal tunnel syndrome; MRI, magnetic resonance imaging.

\section{Discussion}

Focal neuropathy affecting the distal segment of the median nerve at the wrist, known as CTS, has a voluminous literature. ${ }^{4-8}$ Its symptom complex, however, needs to be reassessed and redefined because the treatment and prognostication of this common condition may be affected by the nature, origin, and severity of the symptoms. Moreover, any scientific studies that deal with the outcome of treatment, surgical or nonsurgical, must take into consideration that not all symptoms in the upper extremity are related to median nerve compression. The pain related to median compression frequently occurs simultaneously with numbness and paresthesias especially during nocturnal hours. However, pain related to irritation and inflammation of the tendons, ligaments, and joints is characterized by local tenderness that intensifies with motion. Therefore, it is logical to expect resolution of median nerve-related symptoms following CTS, regardless of surgical approach, and to expect persistence of musculoskeletal pain that is unrelated to median nerve compression. Thus, it behooves the health care providers to educate patients on which symptoms may be expected to resolve following surgery and which may not. Perhaps, this particular treatment outcome should be routinely discussed with the patients when they give their consent to surgery to avoid misunderstandings between patients and physicians.
The selection of patients for surgical and nonsurgical treatments requires a careful assessment of clinical symptomatology. Much emphasis has been placed on the value of electrodiagnostic study on the diagnosis of CTS. In our experience, the clinical symptoms of CTS do not parallel the electrophysiologic abnormalities. Other investigators have had a similar experience. ${ }^{9}$ One study has shown that preoperative nerve conduction values in job-related CTS were either normal or only mildly abnormal, and the postoperative outcomes were poor in this group of patients..$^{10}$

In patients with prominent musculotendinous pain in the wrist with mild electrodiagnostic abnormalities, treatment with steroid injection is more appropriate, as we found in some of our cases. There were situations when both local pain and tenderness and median nerve-related symptoms improved following steroid injection, attesting to local inflammation that characterizes mechanical stress syndrome. Some other patients required surgical decompression when symptoms of median nerve compression recurred, severity of which was more pronounced than musculoskeletal pain. In yet other cases, symptoms related to musculoskeletal irritation and symptoms related to median nerve compression resolved at the same time following surgery. However, the resolution of musculoskeletal pain was likely related to rest and immobilization postoperatively because they did recur 
during resumption of regular physical activities, regardless of etiology.

Occurrence of CRPS following hand surgery is problematic, and it can complicate matters especially in job-related situations. ${ }^{11}$ This condition is a well-known entity characterized by allodynia and vasomotor symptoms in the affected extremity. It is often the cause of protracted or permanent disability. It seems apparent that those cases of CTS with prominent musculoskeletal pain may be at risk of developing this condition as observed previously, ${ }^{1}$ including three in the present study. None of our postoperative cases without musculoskeletal pain and tenderness in the wrist developed this painful condition, regardless of etiology. Although no firm conclusion can be drawn from this association, it is incumbent upon the clinicians and surgeons to be proactive when dealing with the symptom complex of CTS, especially when local musculoskeletal pain is out of proportion to median nerve-related symptoms.

It is clear from the present study that CTS with concurrent and prominent musculoskeletal pain should be considered a separate entity and should be appropriately termed "mechanical stress syndrome", as distinct from true CTS without associated musculoskeletal pain. Therefore, persistence of local tenderness in the wrist or other parts of the affected extremity following surgery should not be construed as treatment failure, and the success of that surgery should be judged on the resolution of median nerve-related symptoms, as illustrated by the postoperative cases of true CTS in the present study.

The persistence of local pain and tenderness in workrelated mechanical stress syndrome, despite resolution of median nerve-related symptoms and normalization of electrodiagnostic abnormalities, has important legal implications. It is quite problematic when persistent pain develops following surgery. The presence of musculoskeletal and soft tissue pain in various parts of the upper extremity can be somewhat difficult to ascertain from the legal standpoint, except when allodynia and vasomotor symptoms secondary to CRPS are present. The treating health care providers are then left providing the various third parties, including the court system, with clinical evidence only - that is, without corroborative laboratory findings. Such a scenario can lead to court decisions that are unfairly favorable or unfavorable to patients, employers, and third parties. However, the use of thermal imaging, also known as thermography, would have been useful to provide objective findings that would correlate with musculoskeletal and soft tissue pain. ${ }^{12,13}$ Unfortunately, this laboratory procedure is still beset with controversies and is not widely recognized as a valid test for quantitative assessment of pain. One of the authors (RPL), a board-certified neuromuscular thermographer, who practiced thermography in the past, found this procedure useful and reliable in the diagnosis of local musculoskeletal and soft tissue pain. This procedure, however, was not utilized in the present study due to bureaucratic and health insurance issues. Nevertheless, our experience and expertise in the clinical and electrophysiologic diagnosis of peripheral neurological and musculoskeletal disorders made it easier for us to establish the diagnosis of musculoskeletal and soft tissue pain in our patients - a diagnosis that is recognized medically and legally. Prospective and collaborative studies may shed more light on this issue.

Why symptoms of median nerve compression occur exclusively and without clinically overt musculoskeletal pain, or vice versa, in some people engaged in occupations that require repetitive motion of the hands, needs explanation. Physioanatomical and mechanical variations in the wrist may be relevant but intrinsic factors within the parenchyma of the median nerve, as in diabetes and hypothyroidism and prior history of median nerve injury secondary to wrist fractures, are equally relevant. Tolerance to pain and the role of the central nervous system in the perception and processing of pain are important factors too. Theoretically, all tissues - muscles, ligaments, tendons, joints, and nerves - should be affected more or less equally and generate local pain and tenderness and peripheral nerve-related symptoms to a similar degree. As shown in the present study, this appears to be not the case. Some of our patients experienced chronic musculoskeletal pain for a long period before developing symptoms of median nerve compression exclusively, months or years after avoiding mechanical stress at work; two of our patients developed De Quervain tenosynovitis which persisted despite resolution of median nerve-related symptoms following surgery; and, interestingly, some of our cases who presented initially with prominent symptoms of median nerve compression never developed overt or disabling musculoskeletal pain. Although CTS had been studied extensively and some facts seemingly well established and recognized by various health care providers and laypersons, there are still some unanswered questions that continue to linger. ${ }^{14-16}$

We, therefore, conclude that the diagnosis and treatment of CTS must take into account the presence of symptoms predominantly related to median nerve compression and those that are related to mechanical stress on the musculoskeletal compartment including the soft tissues and the median nerve itself. We feel, with firm conviction, that the former is a true 
representation of CTS while the latter should be properly termed "mechanical stress syndrome" which has a different treatment approach and prognosis.

\section{Acknowledgment}

The authors thank Scribendi Inc of Ontario, Canada for editing the paper.

\section{Disclosure}

The authors report no conflicts of interest in this work.

\section{References}

1. Lazaro RP. Neuropathic symptoms and musculoskeletal pain in carpal tunnel syndrome: prognostic and therapeutic implications. Surg Neurol. 1997;47(2):115-119.

2. Lazaro RP, Rollinson RD, Fenichel GM. Familial cramps and muscle pain. Arch Neurol. 1981;38(1):22-24.

3. Stransky M, Rubin A, Lava NS, Lazaro RP. Treatment of carpal tunnel syndrome with vitamin B6: A double-blind study. South Med J. 1989;82(7):841-842.

4. Atroshi I, Gummesson C, Johnsson R, Ornstein E, Ranstam J, Rosen I. Prevalence of carpal tunnel syndrome. JAMA. 1999;282(2):153-158.

5. Bickel KD. Carpal tunnel syndrome. J Hand Surg Am. 2010;35(1): $147-152$
6. Graham B, Regehr G, Naglie G, Wright JG. Development and validation of diagnostic criteria for carpal tunnel syndrome. J Hand Surg Am. 2006;31(6):919-924.

7. Lozano-Calderon S, Anthony S, Ring D. The quality and strength of evidence for etiology: Example of carpal tunnel syndrome. J Hand Surg Am. 2008;33(4);525-538.

8. Werner RA. Evaluation of work-related carpal tunnel syndrome. J Occup Rehabil. 2006;16(2);201-216.

9. Glowacki KA, Breen CJ, Sachar K, Weiss AP. Electrodiagnostic testing and carpal tunnel release outcome. J Hand Surg Am. 1996;21(1): $117-121$.

10. Higgs PE, Edwards DF, Martin DS, Weeks PM. Relation of preoperative nerve-conduction values to outcome in workers with surgically treated carpal tunnel syndrome. J Hand Surg Am. 1997;22(2):216-221.

11. Li Z, Smith BP, Tuohy C, Smith TL, Koman LA. Complex regional pain syndrome after hand surgery. Hand Clin. 2010;26(2):2281-2289.

12. Aubry-Frize M, Quartey GRC, Evans H, LaPalme D. The thermographic Detection of Pain. In Proceedings of the 3rd Clinical Engineering Conference: September 1981; Saskatoon, Canada. 1981;82-83.

13. Hubbard J. Hoyt C. Pain evaluation in 805 studies by infrared imaging. Thermology. 1986;1:161-166.

14. Lo SL, Raskin K, Lester H, Lester B. Carpal tunnel syndrome: a historical perspective. Hand Clin. 2002;18(2):211-217.

15. Nora DB, Becker J, Ehlers JA, Gomes I. What symptoms are truly caused by median nerve compression in carpal tunnel syndrome. Clin Neurophysiol. 2005;116(2):275-283.

16. Zanette G, Marani S, Tamburin S. Extra-median spread of sensory symptoms in carpal tunnel syndrome suggests the presence of painrelated mechanisms. Pain. 2006;122(3):264-270.
Journal of Pain Research

\section{Publish your work in this journal}

The Journal of Pain Research is an international, peer reviewed, open access, online journal that welcomes laboratory and clinical findings in the fields of pain research and the prevention and management of pain. Original research, reviews, symposium reports, hypothesis formation and commentaries are all considered for publication.

\section{Dovepress}

The manuscript management system is completely online and includes a very quick and fair peer-review system, which is all easy to use. Visit http://www.dovepress.com/testimonials.php to read real quotes from published authors. 